\title{
THE LEFT ATRIAL X DESCENT
}

\author{
BY \\ P. G. F. NIXON AND O. POLIS \\ From the Departments of Thoracic Surgery and of Medicine in the General Infirmary, Leeds
}

Received July 28, 1961

In sinus rhythm left atrial pressure falls from its " $a$ " and " $v$ " peaks in " $x$ " and " $y$ " descents. The " $x$ " descent is usually interrupted by a small positive transient, the " $c$ " wave. In atrial fibrillation " $a$ " waves and " $x$ " descents disappear and systolic " $c-v$ " waves remain (Fig. 1). There appears little doubt that " $a$ " waves are caused by atrial contraction, and " $v$ " waves by accumulation of blood in the atrium during ventricular systole. " $c$ " may fairly be attributed to early systolic bulging of the mitral leaflets, and " $y$ " to diastolic atrial decompression.

The cause of " $x$ " descent is not certain. Early systolic movement of the atrioventricular ring towards the apex of the heart has been held responsible by Evans (1941), Bloomfield et al. (1946), Musser et al. (1956), Moscovitz and Wilder (1957), Marshall and Wood (1958), Luisada and Liu (1959), and Radner (1959). Atrial relaxation has been considered the cause by Mackenzie (1902), Ewing (1914), Wood (1956), and Ankeney et al. (1956). An additional possibility, the reduction in intrathoracic pressure from ejection of left ventricular contents, was suggested by Mackenzie (1908) and Hirschfelder (1910). The portion of " $x$ " before " $c$ " has been attributed to atrial relaxation, and the portion after, to descent of the base (Mackenzie, 1908; Wiggers, 1923; Fox et al., 1956; Haller and Morrow, 1955; and Kaplan, 1959).

The " $x$ " descent has been said to disappear in mitral incompetence (Moscovitz and Wilder, 1957; Marshall and Wood, 1958; Rubin and Shah, 1958; Wells, 1958; Ross et al., 1960), and to remain (Wynn et al., 1952; Neustadt and Shaffer, 1959). Goldberg et al. (1957) observed that "x" descents may disappear in the absence of mitral incompetence.

Moscovitz and Wilder (1957) and Ross et al. (1960) believed that "v" ascents began pathologically early in mitral incompetence, but Connolly and Wood (1957) disagreed.

No authors concerned with clinical left atrial pulses except Ankeney and his colleagues appear to have considered the time interval between atrial and ventricular systole, and the purpose of this communication is to describe the effects of varying or prolonged P-R intervals on left atrial " $x$ " descents, and to consider their clinical significance.

\section{Material AND Methods}

Four transeptal left heart catheter records (Nixon, 1960) out of a total of 126 were suitable for study because electrocardiogram $\mathbf{P}-\mathbf{R}$ intervals varied in three and were prolonged in one. All records were obtained during expiratory pauses.

Every patient was disabled from mitral valvular disease, and diagnosis was made from consideration of all the clinical, cardiographic and radiological evidence, and from the findings at right and left heart catheterization. Confirmation of the diagnosis was obtained at operation in all cases except one patient with mitral incompetence, illustrated in Fig. 8, who has not yet had surgical treatment. 


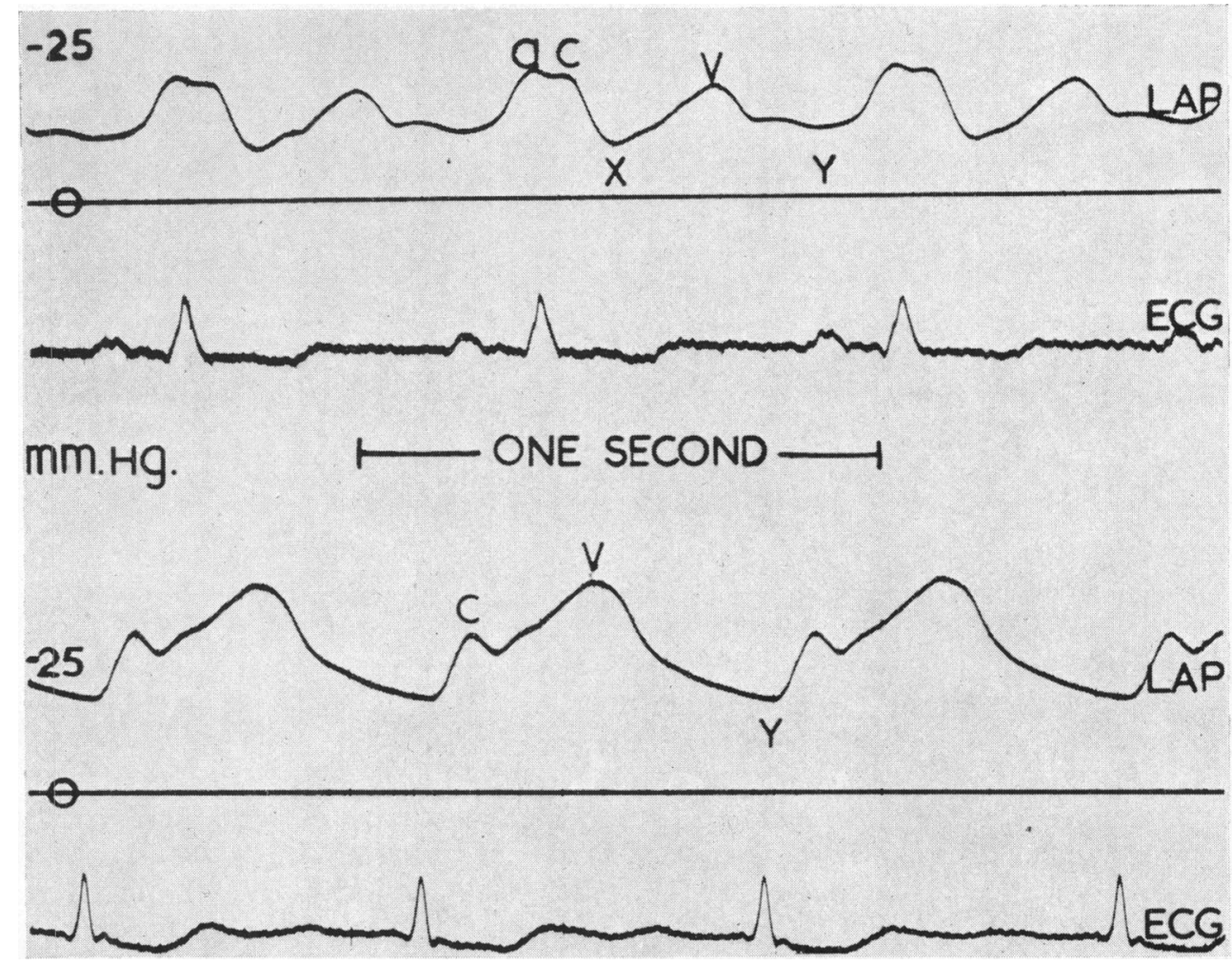

FIG. 1.-Mitral stenosis. Left atrial pulses with simultaneous electrocardiograms. In sinus rhythmupper tracing - " $a$ " waves and " $x$ " descents are present. In atrial fibrillation-lower tracingthere is a "c-v" wave form, and " $a$ " waves and " $x$ " descents are absent. , L.A.P. =left atrial pulse. E.C.G. = lead II electrocardiogram. a, c, v, $x, y=$ left atrial " $a$ " " $c$ " " $v$ " waves and " $x$ " and " $y$ " descents.

\section{RESULTS}

Electrocardiographic R waves and left atrial "c" waves mark the results of ventricular activity, and the time intervals between them were constant during expiratory pauses in the present series of patients with sinus rhythm. The nadirs of " $x$ " descent did not maintain a constant relationship to $\mathbf{R}$ and "c", but varied in time with the cardiographic $\mathbf{P}$ waves and left atrial "a" waves that mark atrial activity.

$P-R$ shortening increases the interval between $R$ and " $x$ " nadir. In the first complex in Fig. 2 (Case 1) the P-R interval is short and the $R-$ " $x$ " nadir interval is long. In the remaining complexes $P$ waves and " $x$ " nadirs occur earlier in relation to $R$ and "c". In Fig. 3 (Case 2) the interval from $P$ to " $x$ " nadir remains constant and the time interval between $R$ or " $c$ " and " $x$ " nadir increases by the amount that P-R shortens. (No " $x$ " descent appears in the fourth complex of this tracing because atrial and ventricular contraction coincide.) In Fig. 4 (Case 3) P-R shortening moves " a" closer to "c" and moves " $\mathrm{x}$ " nadir from a position before to a position after the " $c$ " wave.

$P-R$ lengthening decreases the interval between $R$ and " $x$ " nadir. Fig. 5 (Case 3) shows that as atrial activity occurs earlier the nadir of " $x$ " moves from a position after the " $c$ " wave to a position before it. In Fig. 6 (Case 3) the second P-R interval is longer than the first and "a" and " $x$ " occur earlier. 


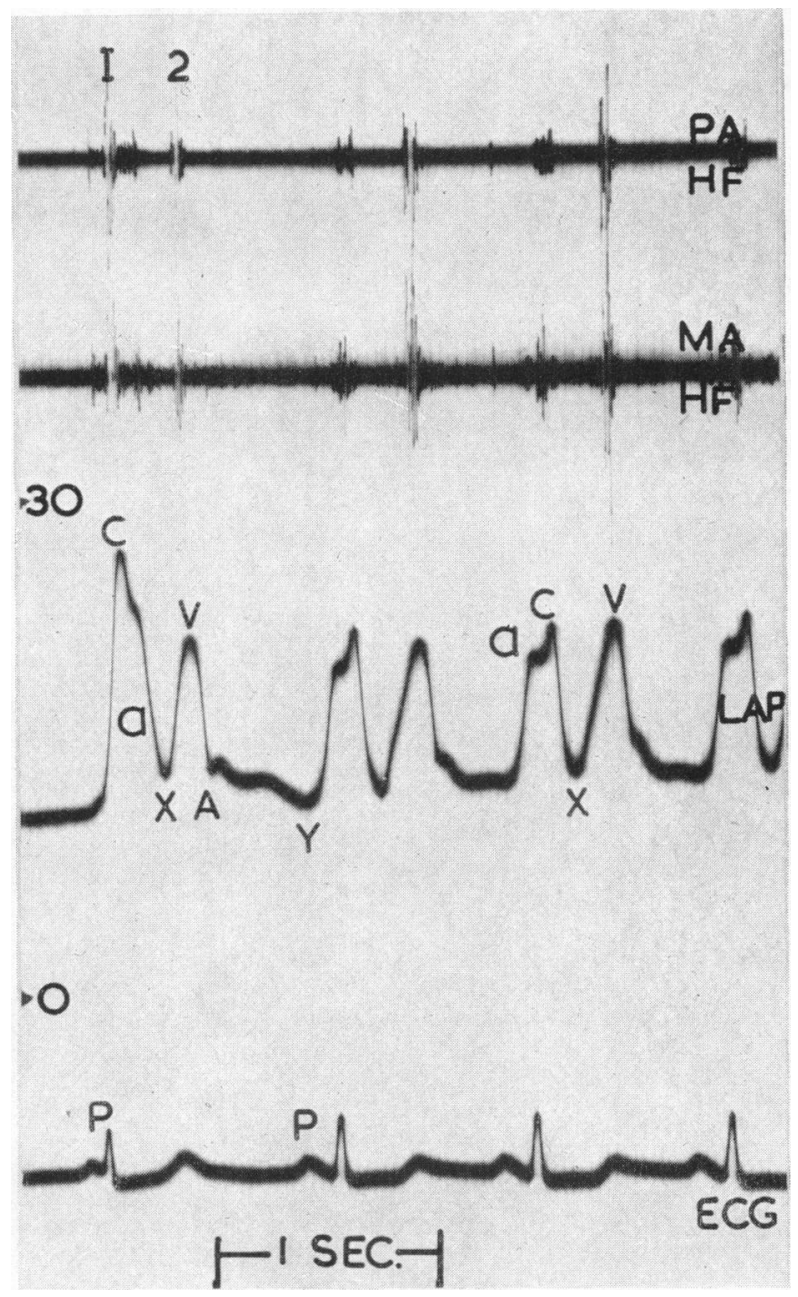

Fig. 2.-Mitral stenosis. Pulmonary area high frequency (PA/HF) and mitral area high frequency (MA/HF) phonocardiogram, left atrial pulse, and lead 2 electrocardiogram. The left atrial pulse is described in the text (Case 1). $\mathbf{P}=$ electrocardiogram $\mathbf{P}$ wave. $\mathbf{A}=$ annular ascent point. Other symbols as for Fig. 1.

When the $\mathbf{P}-\mathbf{R}$ interval is greatly prolonged the " $\mathrm{x}$ " nadir occurs so early that " $c$ " appears as a transient on the upstroke to " $\mathrm{v}$ ", and no pressure trough is seen at the time of annular descent (Fig. 7, Case 4).

It appears from these observations that the timing of the nadir of " $x$ " is related to atrial rather than to ventricular activity.

\section{Discussion}

The disappearance of " $x$ " descents in atrial fibrillation and the present findings strongly support Wood (1956) and Ankeney et al. (1956) in their belief that " $x$ " descents are caused chiefly by atrial relaxation and not by movements of the base of the heart towards the apex. 


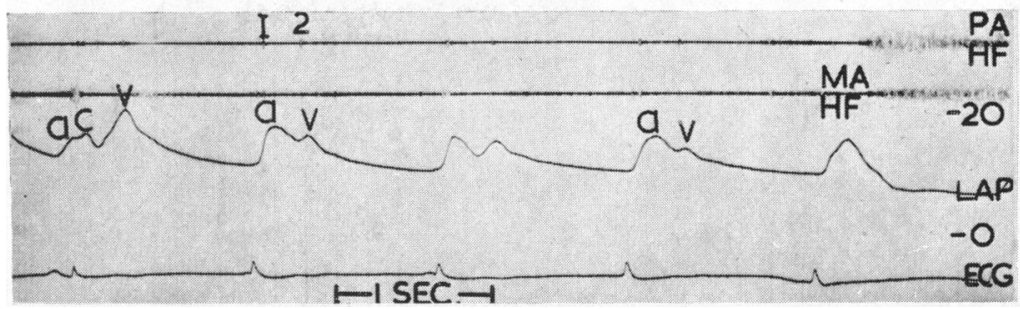

Fig. 3.-Mitral stenosis. Pulmonary area high frequency (PA/HF) and mitral area high frequency (MA/HF) phonocardiograms, left atrial pulse (LAP) and lead 2 electrocardiogram (E.C.G.). The left atrial pulse is described in the text (Case 2). For symbols, see Fig. 1.

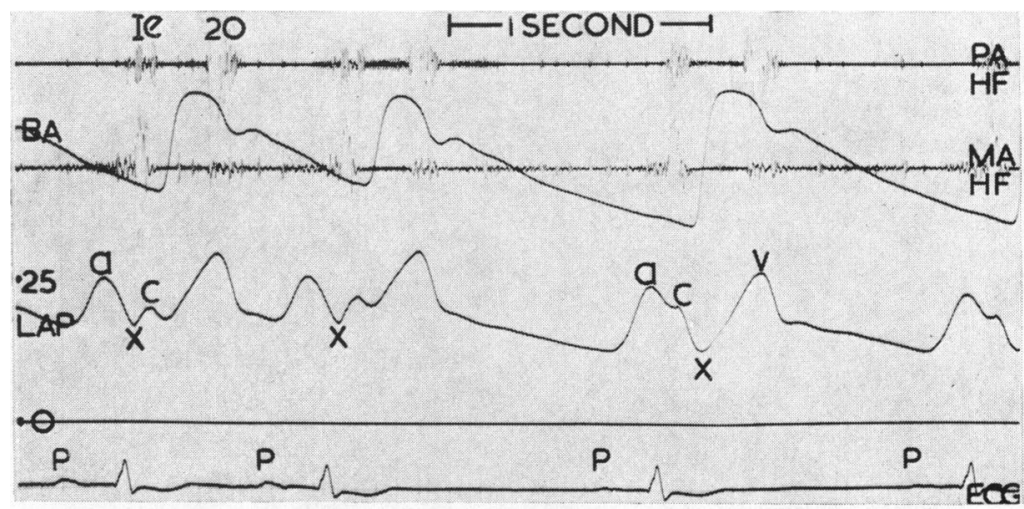

Fig. 4.-Mitral stenosis. Tracings from above downwards: pulmonary and mitral area high frequency phonocardiograms, brachial arterial and left atrial pulses and lead II electrocardiogram. The scale refers to the left atrial pulse. Symbols as for Fig. 1. The left atrial pulse is described in the text (Case 3).



Fig. 5.-Mitral stenosis. Tracings and symbols similar to Fig. 4. The left atrial pulse is described in the text (Case 3). 


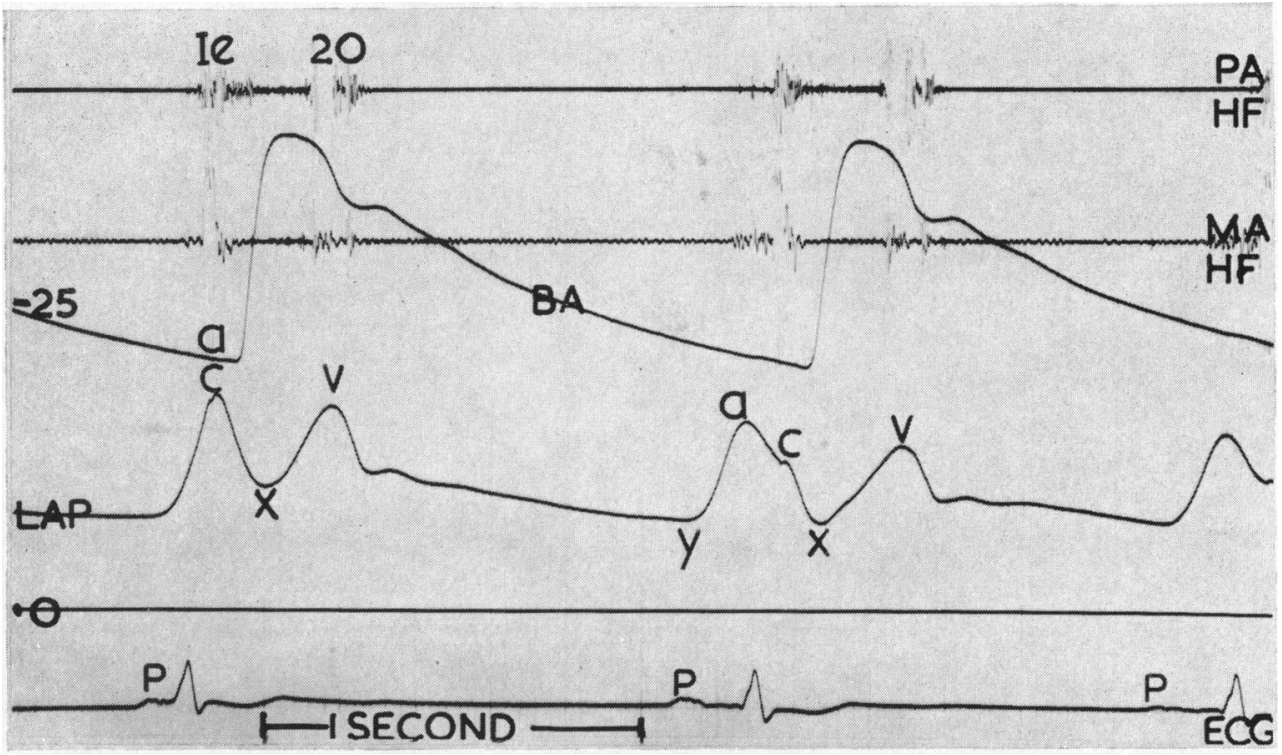

Fig. 6.-Mitral stenosis. Tracings and symbols similar to Fig. 4. e=pulmonary ejection click. $\mathrm{O}=$ opening snap. The left atrial pulse is described in the text (Case 3).

The magnitude of left atrial " $x$ " descent may be affected by numerous factors: atrial systolic and diastolic capacity, elasticity and rate of relaxation; velocity, viscosity and volume of pulmonary venous inflow; regurgitant flow; heart-rate; bulging of the mitral valve; descent of the base of the heart; ventricular diastolic pressure and volume; $\mathrm{P}-\mathrm{R}$ interval, and pressure and traction from surrounding organs. Other things being equal, the pressure recorded in a relaxing heart chamber depends upon filling. If it fills at a greater rate than it relaxes pressure rises, and if it relaxes at a greater rate than it fills pressure falls. Left atrial filling from mitral regurgitation is relatively small in early systole (Wiggers and Feil, 1921-22), and in any case the manometer cannot be expected to discriminate between the pressure changes of pulmonary venous and regurgitant mitral inflow.

Fig. 8 illustrates left atrial pulses from two patients with sinus rhythm and severe disability from mitral incompetence. " $x$ " descents are obvious. Smaller troughs may occur in severe mitral stenosis (Fig. 9). The magnitude of " $x$ " is clearly not a foolproof guide to the presence of incompetence, and it is irrational to use it without reference at least to $\mathrm{P}-\mathrm{R}$ intervals and systemic blood flow.

Wells (1958) studied left atrial " $x$ " descents at operation. His results cannot be compared with cardiac catheterization records at present because thoracotomy has a profound and illunderstood effect upon heart action (Rushmer et al., 1956).

Rubin and Shah (1958) considered " $x$ " descents absent as a rule in mitral incompetence but illustrate their point with a tracing showing long P-R intervals and normal " $x$ " descents occurring before " $c$ " waves. In other

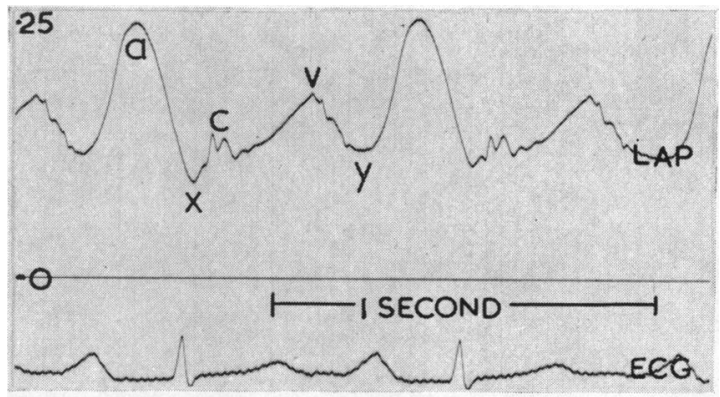

FIG. 7.-Mitral stenosis with trivial regurgitation(Case 4). Left atrial pulse (LAP) and lead II electrocardiogram (E.C.G.). Symbols as for Fig. 1. The P-R interval is prolonged, " $\mathrm{x}$ " nadir occurs early, and " $c$ " appears as a transient on the upstroke to " $v$ ". 

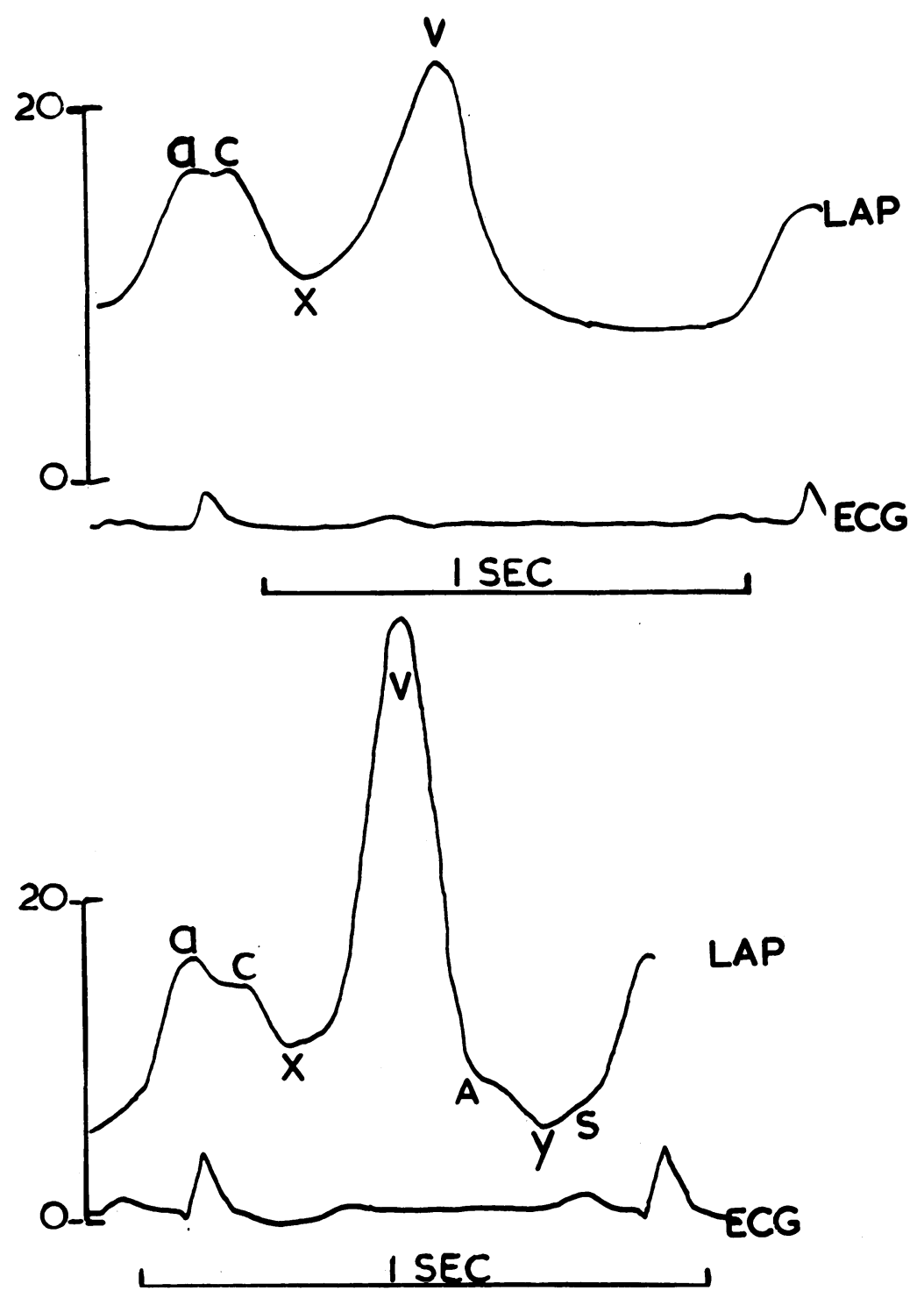

FIG. 8.-Severe mitral incompetence without stenosis. " $x$ " descents are well preserved. $\mathbf{S}=$ stasis wave. For other symbols see Fig. 1 and 2.

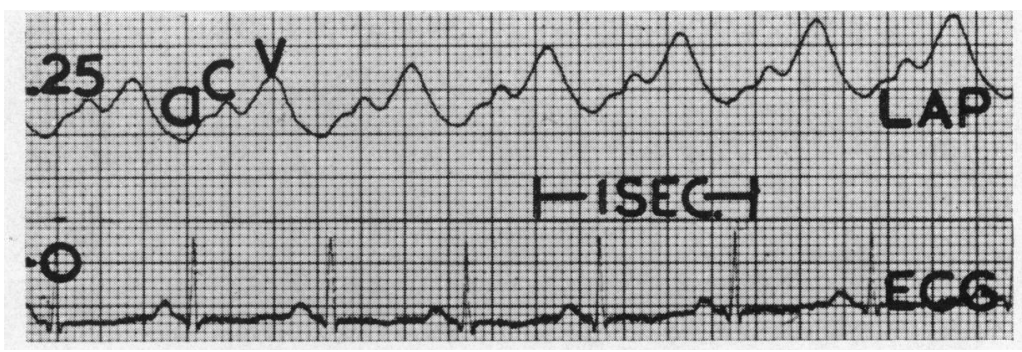

Fig. 9.-Mitral stenosis. Left atrial pulse and electrocardiogram. " $x$ " descents are absent. For symbols, see Fig. 1 and 2. 
words the illustrated " $x$ " descents took place too early to cause depressions between " $c$ " and "v" peaks.

It would seem valueless to record the earliness or lateness of " $\mathrm{v}$ " wave onset without stating whether atrial relaxation has placed the nadir of " $x$ " descent before or after the " $c$ " wave. Ross et al. (1960) did not take atrio-ventricular systolic intervals into account in claiming early " $\mathrm{v}$ " wave onset in mitral incompetence; and their illustration fails to show early " $\mathrm{v}$ " wave onset.

\section{SUMMARY}

Left atrial pressure tracings from cases of mitral valvular disease with changing $\mathbf{P}-\mathbf{R}$ intervals show that " $x$ " descents vary in time with atrial activity and do not maintain a constant relationship to " $c$ " waves or to electrocardiographic $R$ waves. In a patient with prolonged $P-R$ interval no trough of pressure occurred between " $c$ " and " $v$ " peaks. These observations support the belief that atrial relaxation may be chiefly or solely responsible for the " $x$ " descent.

The magnitude of " $x$ " descent is unlikely to be a valuable guide to the presence of mitral regurgitation because it is dependent upon many variable factors.

The authors are deeply indebted to Mr. G. H. Wooler and Professor R. E. Tunbridge for making this study possible. They are grateful to Mr. R. Addyman, Staff Nurse E. M. Kirkbride and Mrs. J. Blake for assistance, and to the Board of Governors of the United Leeds Hospitals, the Medical Research Council and private benefactors for providing equipment.

\section{REFERENCES}

Ankeney, J. L., Fishman, A. P., and Fritts, H. W. (1956). Circulat. Res., 4, 95.

Bloomfield, R. A., Lauson, H. D., Cournand, A., Breed, E. S., and Richards, D. W. (1946). J. clin. Invest., $25,639$. Connolly, D. C., and Wood, E. H. (1957). J. Lab. clin. Med., 49, 526.

Evans, C. L. (1941). Starling's Principles of Human Physiology. J. \& A. Churchill Ltd., London. Ewing, E. M. (1914). Amer. J. Physiol., 33, 158.

Fox, I. J., Wakai, C. S., Connolly, D. C., and Wood, E. H. (1956). Proc. Mayo Clin., 31, 126.

Goldberg, H., Dickens, J., Raber, G., and Hayes, E. (1957). Amer. Heart J., 53, 579.

Haller, J., and Morrow, A. G. (1955). Surgery, 38, 518.

Hirschfelder, A. D. (1910). Diseases of the Heart and Aorta. J. B. Lippincott and Co., Philadelphia and London.

Kaplan, S. (1959). In Intra Vascular Catheterization. Charles C. Thomas, Springfield, Illinois.

Luisada, A. A., and Liu, C. K. (1959). In Cardiology. McGraw-Hill Book Company Inc., New York.

Mackenzie, J. (1902). The Study of the Pulse. Young J. Pentland, Edinburgh and London.

(1908). Diseases of the Heart. Oxford Medical Publications, London.

Marshall, H. W., and Wood, E. H. (1958). Proc. Mayo Clin., 33, 517.

Moscovitz, H. L., and Wilder, R. J. (1957). Amer. Heart J., 53, 741.

Musser, B. G., Bougas, J., and Goldberg, H. (1956). Amer. Heart J., 52, 567.

Neustadt, J. E., and Shaffer, A. B. (1959). Amer. Heart J., 58, 675.

Nixon, P. G. F. (1960). Thorax, 15, 225.

Radner, S. (1959). Acta med. scand., 164, 1.

Ross, J., Jr., Cooper, T., and Lombardo, C. R. (1960). Surgery, 47, 795.

Rubin, M., and Shah, S. (1958). Amer. Heart J., 55, 55.

Rushmer, R. F., Finlayson, B. L., and Nash, A. A. (1956). Circulat. Res., 4, 337.

Wells, B. G. (1958). Brit. Heart J., 20, 321.

Wiggers, C. J. (1923). Circulation in Health and Disease. Lea and Febiger, New York.

, and Feil, H. (1921-22). Heart, 9, 149.

Wood, P. (1956). Diseases of the Heart and Circulation. Eyre and Spottiswoode, London.

Wynn, A., Mathews, M. B., McMillan, I. K. R., and Daley, R. (1952). Lancet, 2, 216. 